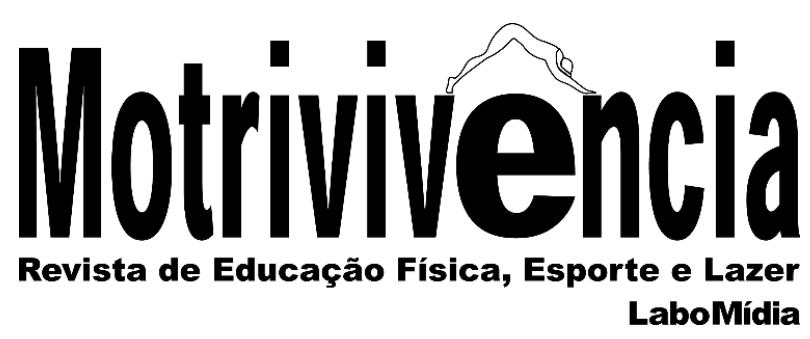

\title{
Reflexões filosóficas em Educação Física: entrevista com o professor Iraquitan de Oliveira Caminha
}

\section{RESUMO}

O texto apresenta entrevista com Iraquitan de Oliveira Caminha, conhecido carinhosamente como "caríssimo". Professor dos programas de Pós-Graduação em Educação Física, e Filosofia da UFPB, é ainda autor de várias obras em Educação Física, Filosofia e Psicologia, além artigos em periódicos científicos e capítulos de livros no universo do corpo, Educação Física, Educação, Psicanálise e Filosofia. Nos concede uma entrevista realizada na UFPB em 05 de dezembro de 2018, a qual nos conta sobre sua trajetória acadêmica e aproximações com o pensamento de Merleau-Ponty. Nos fala ainda sobre suas pesquisas, obras e conceitos engajados nelas e em outros autores como Bachelard, Silvino Santin e Manuel Sérgio. Por fim nos faz um breve relato sobre sua visão acerca dos desafios dos estudos filosóficos da Educação Física.

PALAVRAS-CHAVE: Entrevista; Filosofia; Educação física

\section{Arliene Stephanie Menezes Pereira}

Doutoranda em Educação Instituto Federal de Educação, Ciência e

Tecnologia do Ceará-IFCE

Fortaleza, Ceará, Brasil stephanie_ce@hotmail.com https://orcid.org/0000-0002-3042-538X

Mileyde Bárbara Santos Guedes

Mestre em Educação Física Universidade Federal do Rio Grande do Norte-UFRN

Natal, Rio Grande Norte, Brasil mileyde.barabara@gmail.com https://orcid.org/0000-0003-2710-526X 


\title{
Philosophical reflections in Physical Education: interview with professor Iraquitan de Oliveira Caminha
}

\begin{abstract}
The text presents an interview with Iraquitan de Oliveira Caminha, affectionately known as "very expensive". Professor of the Graduate Programs in Physical Education, and Philosophy of the UFPB, he is also the author of several works in Physical Education, Philosophy and Psychology, besides articles in scientific journals and book chapters in the universe of the body, Physical Education, Education, Psychoanalysis and Philosophy. He gives us an interview at the UFPB on December 5, 2018, which tells us about his academic trajectory and his approximations with the thought of Merleau-Ponty. He also tells us about his research, works and concepts engaged in them and other authors such as Bachelard, Silvino Santin and Manuel Sérgio. Finally he gives us a brief account of his vision of the challenges of philosophical studies of Physical Education.
\end{abstract}

KEYWORDS: Interview; Philosophy; Physical education

\section{Reflexiones filosóficas en Educación Física: entrevista con el profesor Iraquitan de Oliveira Caminha}

\section{RESUMEN}

El texto presenta una entrevista con Iraquitan de Oliveira Caminha, cariñosamente conocido los "very costosos". El profesor de los programas de formación en física de la escuela, Philosophy of the UFPB, también ha sido el autor de varios trabajos en la Educación Física, Filosofía y Psicología, artículos de los artículos en los periódicos de revistas y folletos en el universo del cuerpo, Physical Education, Education, Psychoanalysis and Philosophy. En el caso de Merleau-Ponty, en el caso de Merleau-Ponty, en el caso de Merleau-Ponty. En el caso de que se produzca un cambio en la calidad de la información, La mayoría de las personas que sufren de depresión en el mundo.

PALABRAS-CLAVE: Entrevista; Filosofía; Educación física 


\section{APRESENTAÇÃO}



Fonte: imagem cedida pelo próprio entrevistado

Iraquitan de Oliveira Caminha, conhecido carinhosamente como "caríssimo”, pois é assim que ele se refere ao falar com as pessoas, possui 3 graduações (Educação Física pela Universidade Federal da Paraíba-UFPB-1988, Psicologia pelo Instituto Paraibano de Educação-1990, Filosofia pela UFPB-1995). Iraquitan se tornou Mestre em Filosofia também pela UFPB no ano de 1996. E doutorou-se em Filosofia pela Université Catholique de Louvain na Bélgica em 2001.

Atualmente, é professor-pesquisador do Programa Associado de Pós-Graduação em Educação Física da Universidade Estadual de Pernambuco/Universidade Federal da Paraíba (UPE/UFPB) e do Programa de Pós-Graduação em Filosofia da UFPB. Tendo diversos livros, capítulos de livros e artigos escritos sobre corpo, Educação, Educação Física, Psicanálise e Filosofia.

A discussão sobre temáticas referentes aos estudos socio-filosóficos da Educação Física compõe hoje diversos estudos em várias instâncias acadêmicas, inclusive com linhas específicas nos programas de Pós-Graduação da área. Iraquitan Caminha inclinado aos questionamentos da Educação Física e aos seus parâmetros epistemológicos, imerso nessas indagações, desmistificou as restrições perceptivas sobre a corporeidade, inclinando os seus estudos e pesquisas para afirmar o corpo como totalidade sensível e inteligível. Sua atração para a ciência filosófica de Merleau-Ponty (MP) e sua formação paralela à Educação Física como também na psicologia, permitiu um alicerce teórico para consolidar novos rumos na Educação Física.

$\mathrm{Na}$ época de sua inserção no curso de Educação Física em 1984 era necessário um teste de aptidão física, do qual fora reprovado em seu primeiro vestibular em 1983, na estado de Pernambuco. Hoje com a ampliação teórica nos rumos da Educação Física esse teste não é 
necessário, revelando que as discussões e estudos quebraram muitos dos paradigmas da área, que se revelava como uma ciência puramente mecânica ou fisiológica.

Atualmente o professor Iraquitan prossegue ministrando a disciplina dos Fundamentos Epistemológicos da Educação Física na UFPB para os cursos de licenciatura e bacharelado. Nessa disciplina ele semeia a indagação da Educação Física como uma ciência que se apropria de outras ciências para produzir ciência, não restringe ao esporte, ao corpo, a Educação Física, mas vai além das perspectivas exatas, sociais e de saúde, por estudar o corpo. E estando esse corpo presente em todas as ciências. A Educação Física permeia assim, todas as teorias e dela se apropria. Dessa forma, o desafio da Educação Física e dos estudos para o professor Iraquitan é manter viva as reflexões filosóficas para que o progresso teórico e científico possa prosseguir.

Assim, neste texto apresentamos uma entrevista com depoimentos do professor Iraquitan de Oliveira Caminha realizada na data de 05 de dezembro de 2018, na UFPB; onde o professor nos revela um pouco da sua trajetória na Educação Física, esta que também adentrou a Filosofia e Psicologia, discorrendo também sobre suas obras, ideias e sobre os desafios das reflexões filosóficas em Educação Física.

\section{ENTREVISTA}

Iraquitan de Oliveira Caminha, conhecido carinhosamente como caríssimo”, pois é assim que ele se refere ao falar com as pessoas, possui 3 graduações (Educação Física pela Universidade Federal da Paraíba-UFPB-1988, Psicologia pelo Instituto Paraibano de Educação-1990, Filosofia pela UFPB-1995). Iraquitan se tornou Mestre em Filosofia também pela UFPB no ano de 1996. E doutorou-se em Filosofia pela Université Catholique de Louvain na Bélgica em 2001.

Atualmente, é professor-pesquisador do Programa Associado de Pós-Graduação em Educação Física da Universidade Estadual de Pernambuco/Universidade Federal da Paraíba (UPE/UFPB) e do Programa de Pós-Graduação em Filosofia da UFPB. Tendo diversos livros, capítulos de livros e artigos escritos sobre corpo, Educação, Educação Física, Psicanálise e Filosofia.

A discussão sobre temáticas referentes aos estudos socio-filosóficos da Educação Física compõe hoje diversos estudos em várias instâncias acadêmicas, inclusive com linhas específicas nos programas de Pós-Graduação da área. Iraquitan Caminha inclinado aos questionamentos da Educação Física e aos seus parâmetros epistemológicos, imerso nessas indagações, desmistificou as restrições perceptivas sobre a corporeidade, inclinando os seus estudos e pesquisas para afirmar o corpo como totalidade sensível e inteligível. Sua atração para a ciência filosófica de Merleau-Ponty 
(MP) e sua formação paralela à Educação Física como também na psicologia, permitiu um alicerce teórico para consolidar novos rumos na Educação Física.

$\mathrm{Na}$ época de sua inserção no curso de Educação Física em 1984 era necessário um teste de aptidão física, do qual fora reprovado em seu primeiro vestibular em 1983, na estado de Pernambuco. Hoje com a ampliação teórica nos rumos da Educação Física esse teste não é necessário, revelando que as discussões e estudos quebraram muitos dos paradigmas da área, que se revelava como uma ciência puramente mecânica ou fisiológica.

Atualmente o professor Iraquitan prossegue ministrando a disciplina dos Fundamentos Epistemológicos da Educação Física na UFPB para os cursos de licenciatura e bacharelado. Nessa disciplina ele semeia a indagação da Educação Física como uma ciência que se apropria de outras ciências para produzir ciência, não restringe ao esporte, ao corpo, a Educação Física, mas vai além das perspectivas exatas, sociais e de saúde, por estudar o corpo. E estando esse corpo presente em todas as ciências. A Educação Física permeia assim, todas as teorias e dela se apropria. Dessa forma, o desafio da Educação Física e dos estudos para o professor Iraquitan é manter viva as reflexões filosóficas para que o progresso teórico e científico possa prosseguir.

Assim, neste texto apresentamos uma entrevista com depoimentos do professor Iraquitan de Oliveira Caminha realizada na data de 05 de dezembro de 2018, na UFPB; onde o professor nos revela um pouco da sua trajetória na Educação Física, esta que também adentrou a Filosofia e Psicologia, discorrendo também sobre suas obras, ideias e sobre os desafios das reflexões filosóficas em Educação Física.

\section{Nos conte sobre sua trajetória acadêmica, e de como iniciou os estudos entre a Filosofia e a Educação física (EF).}

Iraquitan: Tive a oportunidade de fazer o curso de EF na década de 80, que foi marcada por fortes discussões acerca da cientificidade da EF. A pergunta que era feita: Quais são as condições e possibilidades da EF ser considerada uma ciência? Nessa ocasião havia muitas discussões correntes. Me recordo bem de uma defendida pelo professor Manuel Sergio que era fazer com que a EF transitasse de um conhecimento de senso comum para um conhecimento científico. Para fazer isso, era necessário estabelecer um corte epistemológico, conceito usado por Bachelard, epistemólogo francês.

A partir desse corte iríamos transitar para construção de uma ciência. No entendimento desse autor, para poder uma ciência se tornar ciência, a primeira coisa era definir qual era seu objeto de estudo. Manuel Sergio, pensador português da Universidade de Lisboa, propõe que o objeto de estudo da EF seja a motricidade humana; não apenas o movimento realizado mecanicamente, mas a 
motricidade. Porque nos jeitos motrizes humanos tem realmente atos motores mecânicos determinados pelas relações causais da natureza. Mas existem atos intencionais, ou seja, o ser humano se constitui no sujeito que é capaz de atos voluntários. Por isso não dava para estudar e criar uma nova ciência com o tema movimento humano. Ele entendia que a noção de motricidade carregava a ideia de que no ato tinha uma intencionalidade. Ele vai buscar essas reflexões em vários pensadores, mas especialmente em Merleau-Ponty. Esse movimento, inclusive, faz gerar a criação de um curso superior na Universidade de Lisboa denominado Ciências da Motricidade Humana.

A partir daí, entrei em contato com essas discussões. Na ocasião, tinha também todo pensamento do pessoal da Universidade do Porto que é muito ligado ao esporte e que não queria fazer esse movimento de transformar a EF na ciência da motricidade humana. Mantendo a ideia de uma espécie de ciência do esporte. Inclusive nessa ocasião tinha toda uma sociedade que congregavam vários pesquisadores, que se chamava Colégio Brasileiro de Ciências do EsporteCBCE; e que existe até hoje. A ideia é tornar o esporte como referência e gravitar em torno dele várias ciências, desde sociologia, antropologia, que são ciências mais humanas incluindo também a psicologia e filosofia e as ciências mais duras, como as ciências biológicas, fisiologia, anatomia, bioquímica. Só que o CBCE ficou voltado para ciências humanas.

Fiz meu primeiro vestibular de EF em Recife. Nasci em 03 de novembro de 1963 em RecifePE, e fiz meu primeiro vestibular para Agronomia, e não passei. Depois fiz para EF e acabei não passando nas provas físicas; porque naquela ocasião, tinha que fazer um teste físico. A ideia que se tinha quando você entrava no curso de música e cursava piano, onde você precisa saber o mínimo de música para poder entrar no curso, também era a mesma mentalidade na EF. Tendo um teste de Cooper, teste de natação e uma bateria de testes de coordenação motora. Acabei sendo reprovado, sobretudo por conta do teste de Cooper, porque tinha um padrão exigido e não consegui cumprir.

Resolvi manter a ideia no ano seguinte de cursar EF e me preparei para fazer os testes. Só que em lugar de fazer em Recife, fiz em João Pessoa, porque meus tios moravam aqui. Então a ideia era ir morar com meu tio. Fiz no UNIPÊ-Centro Universitário de João Pessoa e passei no primeiro período em 1984, onde cursei 2 semestres. Fiz vestibular novamente para fazer EF para a UFPB; passei e entrei em 1985 terminando o curso em 1988.

A partir daí, entrei em contato com toda a discussão das ciências dos esportes, da motricidade humana e ainda tinha outro pensador que pensava que a $\mathrm{EF}$, na verdade, não era uma ciência, sendo uma prática mais próxima da estética das artes. Que era o Silvino Santin, filósofo ligado à fenomenologia. Podemos incorporar a ideia, não somente desses três autores, mas também de que a EF no final das contas não era uma ciência, mas uma prática pedagógica. Na ocasião era 
defendida por Valter Bracht, que tinha todo um grupo de pensadores que se denominavam Coletivo de Autores. Esse coletivo se tornou um livro, até hoje, muito famoso (COLETIVO DE AUTORES, 1992). Tem outros pensadores, como João Batista Freire que pensava na EF, de certa forma também como uma prática pedagógica, mas a influência dele era, sobretudo, Piaget que trabalhava com a cognição juntamente com a motricidade.

Foi nesse cenário que me formei em EF e nesse sentido me interessei pelas discussões epistemológicas e científicas da área. Do ponto de vista prático, me identifiquei com EF escolar e trabalhei inclusive em escolas, como na Luiz Ramalho e na escola Maria de Fátima Souto, as duas no bairro da Mangabeira em João pessoa. Trabalhei também na escola Piolim, e na escola Aldeia. Sempre ministrando aulas de EF escolar, até que decidi retornar a Universidade, mas não ligado a essas discussões. Como tinha interesse em trabalhar com EF infantil, inclusive fiz o curso de especialização nessa área na UFPB, que era uma especialização importante na época, porque havia todo um questionamento da sociedade e da secretaria de educação. Isso, porque nós reivindicávamos que a EF deveria estar presente em todos os níveis da educação básica. Havia um questionamento que os professores de EF não eram preparados para trabalhar com crianças. Diziam: Como vocês querem ministrar aulas pra crianças se vocês não são preparados? A UFPB, como uma forma de reagir a esse questionamento social, iniciou e criou a especialização na Educação Infantil e fui cursar.

Por conta disso, me envolvi muito com a psicologia infantil. Por esta razão fui cursar, também, a graduação em Psicologia no Instituto Paraibano de Educação, onde finalizei em 1990. Me interessei demais pela psicanálise, e fiz a formação em psicanálise social. Só que nunca atuei nesta área.

Trabalhava nas escolas com EF de uma forma diferenciada, a partir dos conhecimentos que adquiri na Psicologia; numa psicologia do desenvolvimento associada a aprendizagem motora, desenvolvimento motor, juntamente com as minhas discussões sobre a EF como ciência. Pensava: Quais são as condições e possibilidades dela realmente se estabelecer como estatuto de ciência? Então, fiquei transitando entre esses dois elementos. Por conta disso, resolvi fazer a graduação em Filosofia, porque descobri que MP era central nesse debate. Por quê? Porque ele fazia todo um debate para desconstruir que o corpo humano era uma máquina, para realizar movimentos mecânicos, e os atos corporais são estabelecidos também por uma ação consciente, por um ato intencional.

Eu entrei como professor da UFPB em 1993; fiz o primeiro concurso para uma vaga e fiquei em $5^{\circ}$ lugar. Eu acho. Fiz o concurso, novamente, para uma disciplina de metodologia da EF no ensino escolar, que era o que eu já fazia nas escolas; era o que eu gostava de fazer. Passei nesse 
concurso em $1^{\circ}$ lugar. Trabalhei com a prática de ensino, assumi a disciplina de filosofia da educação, no centro de educação; já que eu tinha toda uma formação em Filosofia. Trazia os aspectos da EF para essa disciplina, a qual passei muitos anos ministrando, até que surgiu a história da epistemologia e teve uma época que tive que ministrar as bases epistemológicas, ética profissional e fundamentos filosóficos da EF, para o bacharelado e licenciatura. Fiquei sobrecarregado com as disciplinas, veio outro concurso e o colega assumiu.

Penso que a minha trajetória na EF é marcada inicialmente por esses dois caminhos: o caminho do ensino da EF na escola na educação básica e depois reflexões filosóficas, epistemológicas sobre questões e condições da EF como ciência. Isso me fez pensar em uma determinada disciplina que são os estudos socioculturais na EF, nossa linha de pesquisa no Programa de Pós-Graduação.

Entrei no mestrado em Filosofia na UFPB, onde fiz uma dissertação sobre o pensamento de MP acerca do problema da percepção com o título "Reaprendendo o mundo através do corpo: um estudo sobre a experiência perceptiva em Merleau-Ponty" (CAMINHA, 1996). Como se o corpo participasse do processo de percepção do mundo. A percepção do mundo não era só uma condição cognitiva dissociada das ações motores. É uma elaboração do corpo. Só que o corpo não concebido na perspectiva cartesiana, onde separa a coisa física da coisa mental. Temos um corpo, cuja mente é incorporada ao próprio corpo. Foi essa leitura que me fez ter o interesse de estudar fora.

Assim, comecei a estudar francês na aliança francesa, fui sorteado com uma passagem e tive a oportunidade de ir a Paris. Comprei todos os livros em francês de MP e comecei a ler e estudar. Quando terminei o mestrado em 1996, fiz um projeto de tese pra Universidade Católica de Louvain na Bélgica e fui fazer uma tese em 1997 (CAMINHA, 2001). Morei quatro anos na Bélgica, escrevendo sobre MP, exatamente sobre o fenômeno perceptivo na filosofia desse autor. Li toda a obra de MP em francês e fiz minha tese, também, em francês. Ela foi bem acolhida pela Universidade. Obtive inclusive a grande distinção, com uma nota muito boa. Uma nota muito especial!

Voltei para a UFPB, e na reforma curricular nós discutimos a necessidade de ter uma disciplina que, não somente, estudasse a questão dos fundamentos filosóficos da $\mathrm{EF}$, os fundamentos históricos. Mas também, uma disciplina que tratasse dos fundamentos epistemológicos e fui o responsável por essa disciplina. Nela discuto com os alunos sobre as condições de possibilidade da EF ser uma ciência, partindo do princípio que a ciência moderna se estabelece a partir de três fundamentos que são: observação, experimentação e o raciocino lógico. A partir dessa ideia criamos uma reflexão sobre as perspectivas metodológicas e a produção da EF hoje. O meu trabalho atualmente na disciplina é no sentido de construir uma árvore do conhecimento da EF a 
partir do questionamento: “A EF não é uma ciência, mas ela produz conhecimento científico. Então, como ela produz o conhecimento científico apropriando-se de outras ciências?" Só que esse processo de apropriação e de produção de conhecimento nasce no próprio interior da EF, em disciplinas como a fisiologia do exercício físico, a epidemiologia da atividade física, pedagogia do esporte, e dos estudos sócio culturais. Estas são disciplinas nascidas e vindas do interior da área. Depois nós criamos o primeiro Programa de Pós-Graduação em EF UFPB/UPE. Ficou claro pra mim que a Universidade precisa fazer pesquisa, senão perdemos o estatuto de Universidade.

As primeiras iniciativas foram feitas por um conjunto de professores que tentaram criar um Programa de Pós, em conjunto com várias universidades do nordeste. O professor Martins, que foi uma das pessoas que se mobilizou para criar o programa. Só que eram muitas universidades e não tinha como fazer isso. Até que resolveu juntar a UFPB e UPE e tentou comtemplar tanto as áreas mais duras, como bioquímica, fisiologia, esporte, avaliação física, mas também comtemplar os fundamentos pedagógicos e sócio culturais. O programa que tentou abrigar muitas direções científicas e assim, iniciamos o primeiro programa de Pós-Graduação em EF do Norte/Nordeste, a nível de mestrado e depois a nível de doutorado.

Quando retornei do doutorado tive o grande desejo que minha tese fosse publicada, foi um trabalho duro e muito difícil, porque escrevi em francês. Trabalhava feito louco, com o próprio pijama, acordava e começava a trabalhar novamente. O computador ficava ligado direto; eu não desligava. Então, quando voltei não tinha mais saco pra traduzir, mas conheci um francês e ele se propôs a traduzir a tese. Reli toda ela, vendo se havia conexão e corrigindo-a, fazendo reformas. Então, houve um edital na UFPB para publicação de teses e consegui a aprovação pra que fosse publicada em 2010.

Terminei o doutorado em 2001 e só em 2010 a tese foi publicada (CAMINHA, 2010). Desse trabalho surgiram vários artigos, conferências, produções. Meu objetivo nessas conferências era debater sobre o corpo próprio de MP. Nessa ideia de corpo próprio o sujeito deixa de ser um sujeito meramente pensante e passa a ser um sujeito encarnado. Um sujeito que primeiro sente e a partir da sensibilidade ele estrutura o pensamento. Tendo, também, a ver com o mundo. Por que o corpo, como diz MP, tem a ver com a noção de percepção. O corpo próprio e a percepção são os tópicos centrais das minhas discussões. A partir disso, com o Programa de Pós a gente criou a linha dos estudos sócio culturais. Essa linha se apropria das ciências humanas para pensar na diversidade de formas de realização das práticas corporais na sociedade. MP foi muito importante pra mim porque trouxe a perspectiva de deixar o sujeito falar tal como ele vivencia, experiencia, saboreia o ato, tal como ele percebe o corpo; o outro a partir do corpo. 
Com isso, produzimos muitas pesquisas e essas são vistas com uma interrogação. Por exemplo, fizemos um trabalho sobre dança litúrgica, sobre atividade física e transexualidade, o esporte, a homofobia... Pesquisas que trazem problemas sociais e com elas conseguimos excelentes publicações. A única publicação internacional que conseguimos foi ano passado, o capítulo de um livro, de uma pesquisa que fiz voltado pro campo das artes (CAMINHA, 2017). Tive a oportunidade de participar de eventos internacionais com o de Montpellier na França, em Paris. Fiz contato com o meu antigo orientador, professor Michel Dupuis. Tivemos a oportunidade de trazê-lo pro Brasil duas vezes, além de, fazermos contato e conseguimos trazer pra UFPB o professor Jacques Gleyse. Também conseguimos com que um aluno da UFPB, Fábio, fosse cursar o doutorado sanduíche em Montpellier. Tivemos a oportunidade de enviar Ivone e Vera, que são duas ex-doutorandas pra cursar doutorado sanduíche na mesma cidade que estudei. Todos, investimentos que associam a produção acadêmica e a formação de novos pesquisadores. Noção que gosto de fazer, me entusiasmo demais, não restrinjo minha produção a mim, mas a produção de meus alunos, em que sou coautor com eles.

\section{Nos fale sobre essa articulação entre Merleau-Ponty e a EF.}

Iraquitan: Quando a gente fala da EF classicamente o que a gente tem? Que as pessoas devem fazer exercícios físicos regularmente, ou fazer treinamento pra um esporte específico de alto rendimento, ou esporte de lazer. Ou seja, tem um leque de oportunidades. Quando você pensa nessas questões não percebe que tem algo embutido e extremamente importante, que é o conceito de corpo. Se estou treinando pro alto rendimento, se estou praticando uma arte esportiva para o meu divertimento ou se estou fazendo atividade física para melhorar minhas condições de saúde e minha qualidade de vida, de uma certa forma quem está em torno disso é o corpo. Então qual o entendimento que se tem de corpo? Esse foi o motivo pelo qual me aproximei das teorias de MP.

Consigo vislumbrar que tanto na formação dos professores de EF, como nas disciplinas que são as condições de base pra pensar essas atividades corporais, nós temos uma percepção do corpo como estrutura anatômica, biológica e fisiológica. E com estrutura bioquímica; que não se leva em consideração como cada um percebe o seu corpo. O corpo percebido é diferente do corpo explicado pelas ciências biológicas. Então, percebo que tem esse elemento. Por exemplo, se for trabalhar com idosos você diz: vou fazer exercícios físicos pra ajudá-lo na força de seu corpo e prevenir o acontecimento de quedas. Ótimo! Isso é próprio do trabalho do profissional de EF, mas também, é próprio do trabalho de EF uma interação com esse idoso, para que ele fale e expresse o modo como percebe o seu corpo. Pois, essa percepção que o idoso tem de si próprio será decisiva pra trazer pro profissional de EF elementos que permeiem uma prática, uma dimensão biológica, mas também 
uma dimensão pedagógica e sócio cultural. É preciso que o profissional de EF pense que aquele corpo está inserido numa sociedade, ele tem desejos, não se abstém a movimentos mecânicos para o alcance de padrões de saúde ou performance.

Escrevi um texto que iremos publicar, que se chama "Merleau-Ponty e a psicologia". É uma coletânea onde juntamos vários pesquisadores do Brasil que estudam a psicologia em MP. Também estamos organizando a publicação de um livro chamado "Merleau-Ponty e a Educação Física" (NÓBREGA; CAMINHA, 2019). Juntamos vários pesquisadores do Brasil para publicar esse livro e sobretudo os pesquisadores ligados a UFPB e a UFRN, onde nós temos um intercâmbio permanente com as professoras Petrúcia e Karenine, que discutem essas questões.

Uso uma metáfora no meu texto que diz: Que MP me fez dar uma cambalhota na forma que eu via a EF. Via a EF de um jeito, com MP reaprendi a vê-la considerando às questões perceptivas de que o corpo não é um construto de proposições que explicam o seu funcionamento, mas um conjunto de narrativas que expressam como cada um pode ver e perceber o seu corpo. É diferente de um tratado que o explique através de proposições. Penso que isso tem um impacto nos aspectos pedagógicos. Exigir muito mais do professor, porque vai exigir uma atitude diferente. A atitude dele não é somente de repetir, é exigido uma atitude criativa em que adolescentes e crianças passem a revelar e perceber o seu corpo na sua própria peculiaridade narrativa. O professor terá uma espécie de poder sobre sua vida, sobre suas práticas corporais. Você quebra o julgo social que diz como você deve viver e o que deve fazer, a melhor forma de ser, e fica escravo dessa situação. Os corpos são transformados em meros números, em dados, e desconsideram a força subjetiva que tem em cada corpo. Quando pensamos num trabalho coletivo, não consigo ver a exclusão da singularidade de cada um. Destruir a dimensão particular e singular da expressividade. Acho que é uma coisa opressora.

É tanto que o meu próprio modo de funcionamento do laboratório é diferente. Nós ouvimos o outro e nos preocupamos com o desejo individual de cada um sobre suas inquietações, estudos e pesquisas. Tem uma ementa que guia o laboratório, mas tem o ouvir sobre os seus desejos, sobre o que quer pesquisar. O laboratório é um lugar de produção, mas também lugar de liberdade do pensar. Essa liberdade é o respeito pelo modo como as pessoas percebem, o modo como pensam. Trabalhamos nessa direção. Considero que MP traz considerações importantes para a EF em perceber o corpo próprio. Esse corpo próprio está sempre no mundo, há um entrecruzamento.

$\mathrm{Eu}$ e Petrucia iremos escrever um texto, onde tentaremos pensar a produção do conhecimento em EF no entrecruzamento político, estético e ético que é exatamente a noção de carne. A carne é pensar isso entre dois, a relação. É isso que estamos fazendo ao longo do tempo. Mas penso que essa coisa criou mais força com a produção do Programa de Pós-Graduação, porque 
criamos toda uma dinâmica em publicações e tornamos público esse conhecimento e agregando pesquisadores do mundo inteiro e evidentemente que essa interlocução é muito limitada, pois ainda não produzimos textos em inglês.

\section{Nos fale mais sobre o conceito de carne em Merleau-Ponty?}

Iraquitan: O conceito de carne aparece na filosofia de MP quando ele faz uma espécie de transição da fenomenologia para ontologia. A fenomenologia desrespeita a um método, uma atitude em filosofar. Em que consiste a filosofia enquanto método? Consiste em suspender, colocar entre parêntese todas as suas certezas e retomar a experiência. Exemplo: Se pergunto, o que é o corpo? Se vou pra um tratado de físiologia, anatomia e bioquímica, eles vão dizer que o corpo é a junção de órgãos. O fenomenólogo coloca entre parênteses essas certezas e vai retomar a experiência de ser corpo. Há uma coisa que a fenomenologia chama de vivências corporais, interligadas em discurso reflexivo que caracterize o corpo para além dessa exposição meramente explicativa da ciência. $\mathrm{O}$ que MP traz é que a descrição não é suficiente, mas perguntar-se o que é o corpo do ponto de vista do ser corpo. MP recebe toda uma influência de Husserl e Heidgger. Heidgger propõe o problema do ser ontológico e a ontologia estuda o ser. Heidgger diz que a filosofia se dispõe para o ente, que é uma entidade particular, ao fazer suas reflexões. O ser é a totalidade, é o todo. Ele propõe sair da perspectiva fenomenológica e incorporar uma tradição que ele chama de hermenêutica e interpretativa. Ele diz que a fenomenologia esqueceu o ser e é necessário retomar o ser. Ele faz uma discussão sobre verdade de aparência, desvelamento com linguagem, metafórica no envolvimento com as artes, a poesia.

Isso levou MP a produzir um texto sobre a questão da verdade, mas esse texto não foi terminado porque MP morre antes. Ele morre preparando a aula do dia seguinte, em um texto de Descartes, de como percebe o olho, chamado audióptica. O texto que MP escreve em vida chama-se o "Olho e o Espírito" (MERLEAU-PONTY, 2004). Esse texto é um artigo que ele publica para uma revista de estética. Caracteriza uma transição de MP para o conceito de carne, valorizando a expressão, a arte de sentir o corpo. MP vai dizer: não somente sinto algo, aquilo que toco, também sou tocado, aquilo me afeta. Nasce aí a noção de carne. Toco a mesa, e de uma certa forma a mesa me toca, ela não tem sensação como eu tenho. MP retoma uma descrição de Husserl em que as mãos se tocam, dizendo que as duas tocam e são tocadas. É o quiasma que acontece no corpo e não é meramente mental. Por exemplo, olho pra cadeira e ela também me olha, não que tenha olhos, mas que me afeta, a carne pensa no que se passa entre mim e a cadeira, valorizando a presença da cadeira. O que ela me afeta? O que acontece? Ele vai fazer esse debate em torno de uma noção de visível e invisível. Seu aluno organizou os manuscritos e publicou "O Visível e o Invisível" 
(MERLEAU-PONTY, 2000), porque MP já havia morrido. Quando eu olho pra cadeira parece-me que percebo a cadeira, mas quando penso do ponto de vista ontológico, será que você efetivamente percebeu a cadeira? Você vai dizer que não. Porque você percebeu aspectos da cadeira. Tem aspectos invisíveis que você não percebe. Mas o nosso corpo pode movimentar-se, pode ir atrás e entrar em contato com outros elementos; ele começa a ver as coisas de maneira interativa de como se passa esse processo e toda mudança. Sai um pouco das noções de corpo próprio, de consciência, da noção de sujeito pra pensar as relações. Os entrelaçamentos.

Por exemplo, você pensa no contexto da educação e você vai ministrar aula e pensa sobre o corpo próprio, os meus alunos também, mas pra pensar esse corpo próprio eu sou o que percebo. Eu não posso pensar ele o tempo todo isolado, com os adolescestes e todos que me cercam, a temperatura, os diálogos, os diários... O conceito de carne dá abertura para uma perspectiva mais complexa. Chamo isso me apropriando do conceito moderno de rede, penso em rede. Todas as coisas, o nosso pensar, a cadeira, o ambiente, tudo isso constitui uma carne. O filósofo está à procura disso e não apenas descrever como se o mundo fosse passivo e não afetasse. As minhas descrições são fatos dos afetos do mundo. Estar com sede, dor de cabeça interfere em minhas relações. Então é construir uma produção com a preocupação da complexidade em rede, se preocupando com o entre dois o tempo todo. Falei sobre uma parte do texto em que pouco se fala; quando se tira o minério da rocha você diz que o minério foi extraído de lá, mas naquele minério tem traços da rocha nele. O que sou é fruto dos afetos que me afetaram de uma certa forma. O que sou é fruto dos afetos que me afetaram. Inclusive tem uma presença forte da psicanálise pensar as conexões. O meu presente depende de como foi o meu passado. Estão conectados. O exercício de considerar o outro. Se preocupar com a interação.

\section{Quais os desafios para as pesquisas filosóficas em EF?}

Iraquitan: Manter viva as reflexões filosóficas em pensar o todo, a complexidade o contraditório, considerando o outro. É fácil ser de uma determinada abordagem e ficar nela. Outra coisa é permitir dialogar com outras teorias. Posso dizer que transito em outras áreas, na EF, Filosofia, Psicanálise. É uma formação quiasmática como nos diz MP. Que isso tenha um impacto em minha vida. Nas próprias formações de minha banca convido pessoas de outras áreas, que pensam diferente. Penso em fazer pesquisas com eles, escutá-los. Acho que os laboratórios fazendo pesquisa de forma isolada não é saudável. Têm-se pensadores produzindo a partir de seu ponto de vista, mas não se dispõem a produzir com outros pensadores. Sei que tem os limites disso, pois são visões diferentes, mas procuramos a complexidade da totalidade. Não podemos fugir desse debate. 
Do que adianta eu afirmar categoricamente que a vida humana é fundamentalmente sócio cultural e não admitir que tem uma dimensão física, fisiológica, química, matéria? Não posso simplesmente me apegar a minha visão de mundo sem estabelecer essas conexões. Ao estacionar, dirigir e deligar o carro percebo que tem coisa material tem coisa fisiológica. Quando tive uma sincope em que desmaiei, tem a matéria, mas não vivemos apenas no mundo das relações causais, vivemos no mundo de possibilidades. Mas o mundo de possibilidades também é um mundo de frustração, de risco. Nós marcamos a entrevista isso é uma possibilidade. Poderia ter ocorrido interrupções que não a permitissem acontecer. E se não ocorresse, como enfrentaríamos isso? Tem um quiasma entre o mundo possível, o mundo das possibilidades, o mundo determinado pela matéria, pela física, pela química, é isso.

O meu desafio é manter o contato com os meus colegas que pensam diferente. Agradeço a oportunidade de poder compartilhar essa história!

\section{REFERÊNCIAS}

CAMINHA, Iraquitan de Oliveira. Le corpos comme chair du monde et Ll'art comme création. IN: Bernard Andrieu e Nóbrega, Terezinha Petrucia da. (Org.). Au travers du vivant: dans lesthésiologie, Lérmersiologie. 1ed.Paris: L'Harmatttan, 2017, v. 1, p. 207-219.

CAMINHA, Iraquitan de Oliveira. O distante-próximo e o próximo-distante: corpo e percepção na filosofia de Merleau-Ponty. 1. ed. João Pessoa: Editora Universitária da UFPB, 2010. v. 1.

CAMINHA, Iraquitan de Oliveira. Perception et apparaître chez Merleau-Ponty. 2001. Doutorado em Filosofia. Université Catholique de Louvain, UCL, Bélgica.

CAMINHA, Iraquitan de Oliveira. Reaprendendo o mundo através do corpo: um estudo sobre a experiência perceptiva em Merleau-Ponty. Mestrado em Filosofia. 1996. Universidade Federal da Paraíba, UFPB, Brasil.

COLETIVO DE AUTORES. Metodologia do Ensino de Educação Física. São Paulo; Cortez, 1992.

MERLEAU-PONTY, Maurice. O olho e o espírito. São Paulo: Cosac \& Naify, 2004.

MERLEAU-PONTY, Maurice. O visível e o invisível. São Paulo: Editora Perspectiva, 2000.

NÓBREGA, Terezinha Petrúcia da; CAMINHA, Iraquitan de Oliveira. (Org.). Merleau-Ponty e a Educação Física. 1. ed. São Paulo: LiberArs, 2019. v. 300. 


\section{NOTAS DE AUTOR}

\section{AGRADECIMENTOS}

Agradecimento ao Professor Iraquitan de Oliveira Caminha por ter aceitado e cedido esta entrevista com tanto carinho.

\section{CONTRIBUIÇÃO DE AUTORIA}

Não se aplica.

\section{FINANCIAMENTO}

Não se aplica.

\section{CONSENTIMENTO DE USO DE IMAGEM}

Não se aplica.

\section{APROVAÇÃO DE COMITÊ DE ÉTICA EM PESQUISA}

Não se aplica.

\section{CONFLITO DE INTERESSES}

Não há conflito de interesses.

\section{LICENÇA DE USO}

Os autores cedem à Motrivivência - ISSN 2175-8042 os direitos exclusivos de primeira publicação, com o trabalho simultaneamente licenciado sob a Licença Creative Commons Attribution Non-Comercial ShareAlike (CC BY-NC SA) 4.0 International. Esta licença permite que terceiros remixem, adaptem e criem a partir do trabalho publicado, desde que para fins não comerciais, atribuindo o devido crédito de autoria e publicação inicial neste periódico desde que adotem a mesma licença, compartilhar igual. Os autores têm autorização para assumir contratos adicionais separadamente, para distribuição não exclusiva da versão do trabalho publicada neste periódico (ex.: publicar em repositório institucional, em site pessoal, publicar uma tradução, ou como capítulo de livro), com reconhecimento de autoria e publicação inicial neste periódico, desde que para fins não comerciais e compartilhar com a mesma licença.

\section{PUBLISHER}

Universidade Federal de Santa Catarina. Programa de Pós-Graduação em Educação Física. LaboMídia - Laboratório e Observatório da Mídia Esportiva. Publicado no Portal de Periódicos UFSC. As ideias expressadas neste artigo são de responsabilidade de seus autores, não representando, necessariamente, a opinião dos editores ou da universidade.

\section{EDITORES}

Mauricio Roberto da Silva, Giovani De Lorenzi Pires, Rogério Santos Pereira

\section{HISTÓRICO}

Recebido em: 02 de junho de 2019.

Aprovado em: 03 de novembro de 2019. 